\title{
Rationing: the loss of a concept
}

\section{Hugh Upton}

\section{Correspondence to}

Dr Hugh Upton, College of Human \& Health Sciences,

Swansea University, Swansea SA2 8PP, UK:

h.r.upton@swansea.ac.uk

Received 25 August 2010 Revised 12 December 2010

Accepted 16 January 2011 Published Online First

15 February 2011

\section{ABSTRACT}

In the literature on the subject there is a trend towards understanding the idea of rationing in healthcare very broadly, to include any form of restriction in supply. It is suggested in this paper that there are good reasons to resist this move, since it would both render the concept redundant through being trivially true and displace an earlier, egalitarian one that retains great moral significance for the supply of healthcare. The nature and significance of the narrower, egalitarian conception is set out, drawing particular attention to the fact that it marks a contrast with the idea of prioritising certain people or groups over others and to the fact that it is a form of rationing that is plausibly regarded as a morally desirable response to severe shortages. It is contrasted with the broad conception and arguments in favour of this latter are considered and rejected.

\section{INTRODUCTION}

It is a familiar aspect of the debate over the supply of healthcare that the term 'rationing' is now often used in a very broad sense, to cover a wide variety of ways in which the supply might be restricted. Though not yet entrenched in ordinary language, this broad conception of rationing (hereafter referred to as BCR) has become well-established in the literature. In 1979, for example, David Mechanic classified the market as a rationing process, albeit one in need of replacement where healthcare resources were concerned. ${ }^{1}$ In $1994 \mathrm{AB}$ Shaw advocated preferential allocation of healthcare resources to younger rather than older patients and referred to age as 'an objective factor in rationing decisions'. 'Under 'Methods of rationing', Shaw also included chance (such as through the use of a lottery), queueing (in which patients are treated in order of presenting with the problem), market forces, cost effectiveness and prioritising as determined by public opinion. More recently, E Matthews and E Russell ${ }^{3}$ also conceive of healthcare rationing in this way, covering any differential allocation within the overall budget with respect to particular conditions or groups in the population. On their conception, we should note, 'prioritising' is simply a specific form of rationing. TL Beauchamp and JF Childress ${ }^{4}$ also take a broad view, including under rationing both the restriction by price in a market economy as well as the restrictions deriving from social policies. They too treat the prioritising of healthcare resources as a kind of rationing, while Chris Ham and Glenn Robert simply treat the terms as interchangeable. ${ }^{5}$

In contrast to this, I would like to argue for two claims. The first is relatively straightforward. It is that the move to such a BCR effectively renders the concept redundant, referring to nothing more than what has traditionally been discussed under 'resource allocation' or 'distributive justice'. Understood in this way rationing seems unavoidable, ${ }^{6}$ but almost by definition. ${ }^{7}$ This might not matter, but for the second claim. It is that to subsume every mechanism that restricts access to healthcare under such an indiscriminate concept of rationing threatens to obscure what is arguably the single most important moral distinction in the restriction of access to healthcare, particularly where it is publicly-funded: that between policies that prioritise some citizens over others and those that reject this and aim instead at some form of egalitarianism. The problem is not just that BCR includes both and thus fails to distinguish them. It is that by coming to be adopted as our idea of rationing, it will thereby supplant the very concept that most naturally captures the distinction: the much narrower egalitarian conception of rationing (hereafter ECR) familiar above all from the practice of rationing in wartime. Nor is this simply a trivial linguistic matter, since the disappearance of a concept can conceal a related moral problem; in this case the difficult but important one of working out what would constitute an egalitarian distribution of scarce public resources in the context of healthcare. Overall, then, the proposal of this paper will be that the moral significance of the distinction between egalitarianism and prioritising warrants a re-assertion of the narrower conception of rationing (ECR), one that actually reflects rather than obscures this distinction. This would leave us with a conceptual framework comprising, on the one hand, a familiar and morally significant idea of egalitarian rationing and, on the other, the equally morally significant idea of prioritising some people or groups over others.

\section{AN EGALITARIAN CONCEPTION OF RATIONING}

It may be helpful to begin by presenting the general conception of ECR in outline before noting the significance of the moral position that it embodies. First, it relates to a distribution that includes the micro level, reflecting a concern with what is allocated to individual people. Second, it is not merely a process that restricts access to goods but a policy that is directly intended to allocate goods to needs in a specific way; in John Butler's terms, an explicit form of rationing by entitlement (p13). ${ }^{8}$ Third, in virtue of embodying an egalitarian principle of fairness, it aims to avoid abandoning anyone. To this end it will either adopt a policy of straightforward equality in distribution, or, if not this, it will aim to justify any variation by further considerations that are consistent with egalitarian objectives. ${ }^{9}$ Lastly, like any plausible egalitarian distributive principle, it aims not merely at equality $^{10}$ but equality at a useful level, where this 
most obviously involves the provision of at least a basic minimum for all. It is then a further question what other needs, above that level, should be met on an egalitarian basis.

It is this conception of rationing that is at work when the small group of survivors struggle through the desert, eking out their water supplies, every so often passing the bottle round for one drink, and only one, per person. Or, as mentioned, there is the example of rationing in time of war. In the case of food this would involve the supply of at least enough calories for each person's survival at a reasonable level of health. Where there is any variation in a straightforward allocation of equal calories for all, the appropriate form of justification is one that refers to more complex considerations of equality. This might involve the unequal needs that result from such differences between persons as being very young or being involved in heavy labour, where these can be seen as falling directly under a principle of equality: that of supplying equal calories for equal needs. Of course, under conditions of severe scarcity, some demands on food (choosing to run marathons, perhaps) might be judged unacceptable as a basis for an unequal share, but once those activities are ruled out, the expectation will be that everyone's remaining needs will be met.

This brings us to the moral significance of ECR. The crucial point, I suggest, is that this rationing is distinct from prioritisation, where the latter comprises those mechanisms that restrict supply so as to leave (whether intentionally or just foreseeably) some of the population better off than others. This happens most obviously where it is directly intended, as where the young are given preference over the old. It can also happen indirectly, as where we distribute goods by market forces. By contrast, even where ECR leads to different amounts of food being provided in response to different ages or workload, it does not cross the moral boundary of giving any priority or higher status to anyone in the group, and nor does it depend on such a move for its rationale. It merely responds to the different needs that are relevant to having the same objective (survival, most basically) for each member of the group. It thereby preserves the idea of equal treatment for all, and thus an ideal of equal worth and equal respect. All are required to make a sacrifice, but no-one is asked to make one larger than another's, nor to make one in order that another's may be reduced.

Clearly, ECR embodies certain moral claims. I am not here referring to the nature of the overall aim of rationing, which perhaps has an uncertain status. That is, if we take the wartime example, it may be argued that the overall aim is that of increasing the chance of a nation surviving through difficult times and that this is not so much moral in nature as a matter of (group) self-interest. Whatever we think about this, though, it is clear that ECR modifies this goal by means of two moral constraints: a concern for the continuing survival of all current members of the group, and a concern that the policies promoting this survival are justified in terms of equal regard for all. Neither of these two requirements is essential to the survival of something like a national group, since, of course, such a group has a continuing identity independent of the survival of any given person among its current membership, and independent also of whether they are treated equally. Both, though, are vital to characterising ECR.

First, the concern for the survival of all current members marks a clear distinction between this concept of rationing and, for example, a policy that might be thought appropriate in very much more straightened circumstances, that of some severe kind of triage (Butler, p47), ${ }^{8}$ where some individuals might (in effect if not intent) be sacrificed to help secure the overall aim of group survival. Those already in a weakened condition might be selected. This kind of triage policy would not necessarily be ruled out by an appeal to equality alone. For example, it might be argued that, precisely in order to uphold fairness and the ideal of equal worth, a lottery should be held to decide who should be sacrificed. Such a policy, while arguably egalitarian in that it gives an equal chance of survival to all, nevertheless constitutes a decision that some must be sacrificed and thus falls foul of the requirement for a concern for the survival of all current members.

Second, there is reason to think that requiring the concern for all to be an equal concern is also a vital condition, since where there is either an unjustified departure from equality, or a departure justified by reference to some principle inconsistent with equality, we are, at least to a degree, sacrificing one or more members of the group. Thus, to make further savings, a sub-group might be selected to receive what was predictably sufficient for survival but only at a lower level of health than others, and therefore at a greater level of risk. By way of defence, it might be said that this did not represent the sacrifice of any current member, but rather that the survival of all remained a concern. Nevertheless, such a policy would not represent an equal concern for the survival of all current members, so that, even if we took this justification to have some weight, it could not be on grounds of an equality of respect for all. Even if it were thought justified by the extreme circumstances, it would amount to at least a degree of disregard of the interests of some current members of the group relative to the rest and thus be inconsistent with the concept of ECR.

As well as noting the moral elements that are partly constitutive of ECR, there is a further important point to be made here, which is that, under conditions of scarcity, rationing of this kind has a strong claim to be morally justified, perhaps even required, however regrettable may be the circumstances under which it becomes appropriate. That is, at least where it is agreed that the scarcity is not remediable and agreed that non-rationed access to the relevant goods constitutes a serious risk to the relevant group, we might well say that it is exactly the right policy. Rather more controversial, perhaps, is the situation where the scarcity results not from unavoidable circumstances but from a political decision about funding. Such a decision, though, would seem to be a separate moral issue, one that does not alter the moral rightness of the rationing, given a reasonable degree of certainty that, for whatever reason, the scarcity will persist.

\section{EGALITARIAN AND BROAD CONCEPTIONS COMPARED}

How, then, does ECR compare with the other restrictions on supply, mentioned earlier, that are now also typically included in the general idea of 'rationing' and so help make up the BCR? One point to note immediately is how very varied are the practices and processes included. PA Ubel, who writes in favour of rationing, is another who supports a broad conception, seeing it as deriving from the usage favoured by economists: 'To them, rationing includes any mechanisms that limit how many goods people receive, including ability to pay'. ${ }^{11}$ So, even if we set aside ECR from these, we are left with a very diverse range of proposals. However, what they crucially have in common, besides the imposition of limits to supply, is that they all constitute ways of sacrificing the welfare of some for the welfare of others. If we briefly revisit those mentioned at the outset, we can first note those that would come within Ubel's category of 'explicit' rationing, where the administrators consciously intend to withhold a service from certain people. 
The idea of the lottery has already been mentioned, together with the fact that it does take some account of fairness. So, in different ways, do principles of distribution based on age ${ }^{12}$ or queueing. Most significantly, though, all three involve the assumption that it is legitimate to decide that some patients (whether unlucky, older or at the back of the queue) will be denied treatment. This is not to say that this could never be justified. Even where the treatment related to basic needs, really extreme circumstances might warrant such a policy. The proposal is rather that we should mark its moral significance by describing this as a point where rationing, understood as embodying a commitment to treating all, becomes impossible, and some more radical policy of prioritising has to be adopted instead.

Of all the explicit forms, though, it is probably the appeal to cost-effectiveness and the role of the National Institute for Health and Clinical Excellence (NICE) that is currently most prominent. Not surprisingly, its work in giving or withholding approval of treatments within the NHS has been highly controversial. However, more to the point here is that, whatever the original intention, NICE's efforts to prioritise on the basis of cost-effectiveness have come to be regarded by many, notably in the press, as part of the process of 'rationing' healthcare. To take one example from The Times, we can note the health editor referring to NICE as 'the government's drug rationing body'. ${ }^{13}$ It is important to be clear, then, that while some assessments of effectiveness could obviously be relevant to ECR, there is nothing intrinsically egalitarian in the usual comparisons of cost-effectiveness in healthcare or in the maximising objectives that typically accompany them.

We can turn now to what Ubel refers to as 'implicit' rationing, where some mechanism restricts access to services but not through any intention that this occur. Here, perhaps, we reach the point furthest from the concept of ECR, since this involves the inclusion of market forces. These seem to meet barely any of the defining features of ECR that were described at the outset. To begin with the most straightforward difference, although free markets are obviously mechanisms that affect distribution at the micro-level, it is evident that they may leave some unable to afford any given product or service. Plainly, then, they do not aim to secure a basic minimum for all. More generally, they do not aim at any specified distribution. In fact, far from constituting a policy intended to produce a particular pattern of distribution the free market has been held by some, famously by Robert Nozick, ${ }^{14}$ to be the morally appropriate form of distribution precisely for abjuring those coercive interventions required to produce a preconceived pattern. The idea of a market is thus strikingly at variance with ECR, but also with what Beauchamp and Childress ${ }^{4}$ refer to as the original concept of rationing. This concept, they suggest, was not necessarily related to severe shortages, but was one that simply referred to the normal allocation of an allowance or portion (eg, rations of food in the army) to the relevant individuals. The workings of the free market seem to have no relation to this sort of planned and measured allocation, beyond, as mentioned earlier, the very general idea that access to the goods concerned is, like that to almost all goods, restricted rather than entirely open.

\section{THE BROAD CONCEPTION: ARGUMENTS AND REPLIES}

Can a positive case be made for the adoption of BCR? Ubel $^{11}$ is noteworthy in attempting this, though in doing so he focuses on the only aspect of it that he regards as conceptually contentious: the extension of the concept of rationing from solely explicit mechanisms to the inclusion of the workings of market forces as well. However, since his defence of the extension has a bearing on ECR, it is relevant here.

To begin, Ubel himself admits ( $p 17)$ that the 'implicit' rationing of the market will be at variance with the 'popular understanding' of the meaning of rationing, but goes on to offer three responses to this discrepancy. First, simply in respect of linguistic usage, he suggests that, given the special place of healthcare in our lives, the popular understanding would change if healthcare was distributed purely on the basis of ability to pay the market price, and we saw more patients suffer from lack of the treatments they could not afford. By way of reply, I suggest that a prediction about a possible change in language does not warrant us in consciously assisting such a change at the expense of an important distinction.

Second, though, he argues that we should in fact choose to include implicit mechanisms in our conception of rationing because the 'deprivation and hardship' that results from a distribution according to ability to pay is something commonly associated with rationing. It is an argument that seems much more significant than the first. This claim, that it is desirable to bring under one broad conception all those distributive mechanisms which produce the hardship we associate with a narrower conception, is one that would undermine the distinction between ECR and other forms of explicit restriction, as much as that between the explicit and implicit. Yet it is an argument lacking a crucial rationale. Why should we organise our concepts to reflect the general outcomes of deprivation and hardship, conditions that unfortunately will result for some of us whatever policies are chosen? Is it not more important to mark those moral distinctions that we use in trying to justify the various mechanisms that partly determine where these outcomes occur and where they are avoided?

Ubel's third response is to claim that it would actually be dangerous to limit our conception of rationing to explicit mechanisms, since this would allow providers of healthcare to withhold services through implicit mechanisms while defending the practice by denying that any rationing was taking place. This response, we should note, involves the familiar but contestable assumption that rationing is always wrong. However, even if we accepted this for the sake of argument, there seems no reason to suppose that, having agreed that no rationing was occurring, we would thereby be rendered oblivious to other wrongs, such as the injustices of the free market. More important, though, is the way in which a reversion to ECR would alter the assumption behind Ubel's third claim. If we reverted to the traditional concept of rationing, where this is a procedure plausibly seen as morally right in the appropriate circumstances, then a claim that rationing was not occurring would of course constitute no defence of public policy at all. In fact, talk of rationing would be irrelevant. Instead (and surely better) the putative service suppliers would have to tackle the problem head on and provide an overt defence of their decision to do nothing regarding the failures of supply arising from implicit mechanisms such as market forces.

\section{CONCLUSION}

Perhaps some will accept the moral significance of ECR but doubt its applicability to something as complex as healthcare. To try to make the case for this in detail is of course a large task and, other than for these brief closing remarks, beyond the scope of this paper. To note one issue, some may baulk at the difficulty of establishing a basic minimum. Yet, in a situation where the supply of publicly funded healthcare is seriously constrained, it would seem morally required of us to at least attempt to 
produce some account of a threshold of this kind. Equally, it may be objected that while everyone needs food, there are those who will not need healthcare at all, and certainly many who will not need any particular form of healthcare that we might specify. Yet this is not in principle a problem for ECR; in wartime, after all, although not everyone needs petrol, where it actually is needed it can be rationed. With healthcare too it is possible to apply the conception across some general kinds of service that not all will use. Just as an example, it might be that for any hospital in-patient treatment there is an ideal length of stay, and a shorter one that is adequate as an (equally supplied) basic minimum. Or, for many drugs, that there are ideal choices and cheaper ones that are adequate. When resources are scarce, ECR requires that, where such savings are possible, they should be made, thus ensuring that, as far as is practically achievable, all users of a given service are making the same kind of sacrifice and none is being abandoned.

It should be said, of course, that these judgements can only be approximate, as will be comparisons of fairness made between the rationing of different treatments. However, the importance of a general principle like ECR lies not in requiring an impossible exactitude of measurement but in directing our attention to the moral basis of our decisions. To take an example, consider the allocation of the H1N1 flu vaccine. Ideally, let us assume, a public health service would make this equally available to all. In circumstances of a shortage, though, it may still be possible to take some approximate account of equality (in this case, equal need) in allocating stocks only to those at greatest risk. By contrast, if we allocate only to healthcare workers on the grounds of the importance of their work in the event of a serious emergency we have left ECR behind and prioritised certain people over others. This is not to deny that there are circumstances that might justify this, but merely to stress the importance of clarity in our reasons for the policy. Thus, I suggest, even where we find ECR displaced by other principles, or even just difficult to apply in some cases, it may still be important in providing a general guiding and justifying conception of what we hoped to achieve, and so establishing the important moral boundary that is crossed, albeit perhaps sometimes defensibly, when instead we prioritise the welfare of some over others.

Acknowledgements My thanks go to Steve Edwards for comments on an earlier version of this paper and to two anonymous reviewers.

Competing interests None.

Provenance and peer review Not commissioned; externally peer reviewed.

\section{REFERENCES}

1. Mechanic D. Future Issues in Health Care: Social Policy and the Rationing of Medical Services. New York: The Free Press, 1979:10-11.

2. Shaw AB. In defence of ageism. J Med Ethics 1994;20:188-91.

3. Matthews E, Russell E. Rationing Medical Care on the Basis of Age: the Moral Dimensions. Oxford: Radcliffe Publishing, 2005:53-4.

4. Beauchamp TL, Childress JF. Principles of Biomedical Ethics. New York: Oxford University Press, 2009:272.

5. Ham C, Robert G. Introduction. In: Ham C, Robert G, eds. Reasonable Rationing: International Experience of Priority Setting in Health Care. Maidenhead: Open University Press, 2003:1-3.

6. Brauer S. Age rationing and prudential lifespan account in Norman Daniels' Just Health. J Med Ethics 2009;35:27-31.

7. Light D, Hughes D. A sociological perspective on rationing: power, rhetoric and situated practices. In: Hughes D, Light D, eds. Rationing: Constructed Realities and Professional Practices. Oxford: Blackwell, 2002:1-19.

8. Butler J. The Ethics of Health Care Rationing. London: Cassell, 1999.

9. Klein R, Day P, Redmayne S. Managing Scarcity: Priority Setting and Rationing in the National Health Service. Maidenhead: Open University Press, 1996:25-6.

10. Cookson R, Dolan D. Principles of justice in health care rationing. J Med Ethics 2000;26:323-9.

11. Ubel PA. Pricing Life: Why it's Time for Health Care Rationing. Cambridge, Massachusetts: MIT Press, 2001.

12. Menzel P. Allocation of scarce resources. In: Rhodes R, Francis LP, Silvers A, eds The Blackwell Guide to Medical Ethics. Oxford: Blackwell, 2007:305-22.

13. Templeton SK. 10,000 Set to Pay For Top-Up Cancer Drugs: The Times online, 2008. http://www.timesonline.co.uk/tol/news/uk/health/article5014523.ece (accessed 10 May 2010).

14. Nozick R. Anarchy, State, and Utopia. Oxford: Blackwell, 1974. 